\title{
Drilling Polymeric Matrix Composites
}

Edoardo Capello ${ }^{1}$, Antonio Langella ${ }^{2}$, Luigi $\mathrm{Nele}^{2}$, Alfonso Paoletti ${ }^{3}$, Loredana Santo $^{4}$, Vincenzo Tagliaferri ${ }^{4}$

${ }^{1}$ Dipartimento di Meccanica, Politecnico di Milano, piazza Leonardo da Vinci 32, 20133 Milano, Italy.

E-mail: edoardo.capello@polimi.it

${ }^{2}$ Department of Materials and Engineering Production, University of Naples Federico II, Piazzale Tecchio 32, 80125 Napoli, Italy.

E-mail: antgella@unina.it, luigi.nele@unina.it

${ }^{3}$ Università di L'Aquila, Piazza V. Rivera 1, 67100 L'Aquila, Italy.

E-mail: alpao@ing.univaq.it

${ }^{4}$ Dipartimento di Ingegneria Meccanica, Università di Roma “Tor Vergata", via del Politecnico 1, 00133 Roma, Italy.

E-mail: loredana.santo@uniroma2.it,tagliaferri@mec.uniroma2.it

This chapter presents the basics of drilling of polymeric matrix composites (PMCs). PMCs are becoming widely used in the manufacturing of products where a high mechanical strength must be accompanied by a low weight. However, the machining of PMCs implies coping with problems that are not encountered when machining other materials. Drilling is a particularly critical operation for PMCs laminates because the large concentrated forces generated can lead to widespread damage. This damage causes aesthetic problems but, more importantly, may compromise the mechanical properties of the finished part.

\subsection{Introduction}

\subsubsection{What Are Polymeric Matrix Composites?}

Composite materials are made up of two or more constituents [1-8]. The principle behind the study of composite materials and their applications is based on the possibility of using materials with specific characteristics which, when joined together in an appropriate manner, create a single composite material with final properties that are not found in any of the raw materials.

One of the constituents, called the matrix, usually determines the characteristics of the composite material primarily according to the field of application, the temperature of use and the weight. Its role is to contain another constituent, called the 
reinforcement, which determines the principal mechanical characteristics of the composite material, tensile modulus and mechanical resistance.

In nature, it is possible to find various examples of natural composite materials, such as bone or wood. An artificial composite material can be obtained using various types of matrix and with various types of reinforcement. The reinforcement may be in the form of filaments, called fibres (long or short), or in the form of particles. In theory, all materials can be used for the production of fibres, but in practice only a limited number of materials can be selected, and even fewer of these have those mechanical characteristics that are of interest in engineering applications.

Both matrix and fibres can be metallic, ceramic or polymeric, and the composite materials, classified according to matrix type, can be divided as follows:

- $\quad$ polymeric composites

- metallic composites

- $\quad$ ceramic composites

Polymeric matrix composite materials (PMCs) have a matrix which is made of a thermoset or a thermoplastic polymeric resin. Polymeric matrices are made up of rigid polymeric chains obtained from liquid monomers by means of a process of chemical transformation known as polymerization.

Thermoplastic matrices are polymers that have polymeric chains without transverse bonds and thus, after polymerization, an increase in temperature leads to a reduction in viscosity and to a melting of the matrix. The melting from a solid state develops through a gummy state, in a manner which is reversible.

Thermoset matrices are, on the other hand, characterized by the presence of strong transverse bonds which are created during polymerization, and which make the process not reversible. Indeed, an increase in temperature after polymerization does not initially generate substantial variations in the matrix properties, while beyond a certain limit it causes the total degradation of the matrix.

With the use of thermoplastic matrices, the component manufacturer uses a semi-finished product in which the polymerization reactions have already taken place and are guaranteed by the producer of the matrix. These semi-finished products need only to be modelled to obtain the required shape for the final component. As opposed to thermoset matrices, the application of thermoplastic matrices in composite materials has, in the past, been hindered by a low softening temperature, a lower tensile modulus and by reduced adhesion between fibres and matrix. Some types of thermoplastic matrices with properties similar to those of thermoset matrices are currently available, but with the prospect of lower transformation costs. The main thermoplastic matrices used in polymeric composite materials are: poly-ether-ether-ketones (PEEKs), poly-phenylene-sulphide (PPS), and poly-etherimide (PEI).

With the use of thermoset matrices, the polymerization process must be carried out during the manufacturing cycle of the component, and this requires a rigid, more careful control of the process. The fact that thermoset matrices are so widely used is due to their strong mechanical properties and to the low cost of the matrices. Moreover, manual and semi-manual processing can be easily performed. 
The most commonly used types of resin are polyester and epoxy. Unsaturated polyester resins have good mechanical characteristics, are easily workable and polymerize at room temperature. Unsaturated polyester resins can be classified according to the constitutional groups that appear in the chain structure. Among the most common are the ortophtalic polyesters, the isophtalics, the bisphenols and the dicyclopentadienyls.

Bicomponent or monocomponent epoxy resins have better mechanical properties compared to polyester resins, although they have a higher cost. Consequently, their application is generally limited to advanced applications in the aerospace industry.

The most commonly used types of reinforcement are glass, carbon and aramidic fibres.

The most common commercial formats of reinforcements for polymeric matrix composites are:

- Mat: The fibres are arranged on a plane in a random manner and are lightly compressed and treated with an adhesive. Alternatively, the unifilo mat can be used, in which a single thread is arranged on a plane in a casual manner. The mats are used to create quasi-isotropic composites with moderate mechanical characteristics;

- Roving: Long fibres are wound around bobbins, from which they are unwound in bundles and used as continuous fibres or cut to obtain short fibres;

- Woven - fabric: Continuous long fibres are braided together to form a bidimensional or tridimensional material;

- Pre-pregs: These are semi-finished products widely used in advanced applications, in which fibres have been impregnated with the right amount of thermoset resin and kept at low temperature, away from the light.

The processes used in the manufacture of polymeric composite materials allow the fibre and matrix volumes to be selected in such a way that particular requirements can be met. The quantity of fibres present usually reaches $60 \%$ of the available volume, while the matrix occupies the remaining $40 \%$. The properties of the composite material obviously depend on the properties of the reinforcement and the matrix (Tables 6.1 and 6.2), and on the quantity of these.

A simple rule to predict in a first approximation a property of the composite is the so-called mixture rule which states that:

$$
P_{c}=P_{f} \cdot V_{f}+P_{m} \cdot V_{m}
$$

in which $P_{c}$ is the resulting property of the composite to be determined, $P_{m}$ and $P_{f}$ are the properties of the matrix and the reinforcement and $V_{m}$ and $V_{f}$ are the volumetric fractions of the matrix and reinforcement present, respectively.

The reinforcement and the matrix are arranged on a plane, forming a so-called lamina in which the fibres (short or continuous) are suspended in the matrix (Figure 6.1). The fibres may be placed casually or they may be aligned. The study of interaction between fibres and matrix is known as micromechanics. 
Table 6.1. Properties of matrices commonly used from polymeric composite materials

\begin{tabular}{|l|l|l|l|l|}
\hline & $\begin{array}{l}\text { Tensile } \\
\text { modulus } \\
(\boldsymbol{E})\end{array}$ & $\begin{array}{l}\text { Tensile } \\
\text { strength } \\
(\boldsymbol{\sigma} \boldsymbol{(}) \\
(\mathbf{G P a})\end{array}$ & $\begin{array}{l}\text { Density } \\
(\boldsymbol{\rho}) \\
\left(\mathbf{g} / \mathbf{c m}^{3}\right)\end{array}$ & $\begin{array}{l}\text { Ultimate } \\
\text { elongation } \\
(\mathbf{\%})\end{array}$ \\
\hline Epoxy & $2.75-4.10$ & $55-130$ & $1.2-1.3$ & $4-8$ \\
\hline Polyester & $2.80-3.50$ & $20-80$ & $1.1-1.4$ & $1,4-4,0$ \\
\hline PEEK & 3.2 & 100 & $130-1.32$ & 50 \\
\hline PPS & 3.3 & 83 & 1.36 & 4 \\
\hline PEI & 3 & 105 & 1.27 & 60 \\
\hline
\end{tabular}

Table 6.2. Properties of fibres commonly used from polymeric composite materials

\begin{tabular}{|l|l|l|l|l|}
\hline & $\begin{array}{l}\text { Tensile } \\
\text { modulus } \\
(\boldsymbol{E}) \\
\mathbf{( G P a )}\end{array}$ & $\begin{array}{l}\text { Tensile } \\
\text { strength } \\
\left(\boldsymbol{\sigma}_{\boldsymbol{u}}\right) \\
(\mathbf{G P a})\end{array}$ & $\begin{array}{l}\text { Density } \\
(\boldsymbol{\rho}) \\
\left(\mathbf{g} / \mathbf{c m}^{\mathbf{3}}\right)\end{array}$ & $\begin{array}{l}\text { Ultimate } \\
\text { elongation } \\
(\mathbf{\%})\end{array}$ \\
\hline Glass E & $80-81$ & $3.1-3.8$ & 2.62 & 4.6 \\
\hline Glass S & $88-91$ & $4.4-4.6$ & 2,48 & $5.4-5.8$ \\
\hline Carbon, low modulus $^{*}$ & $170-241$ & $1.4-3.1$ & 1.90 & 0.9 \\
\hline Carbon, high modulus $^{*}$ & $380-620$ & $1.9-2.8$ & 2.00 & 0.5 \\
\hline Aramidic (Kevlar 29) & 83 & 3.6 & 1.44 & 4.0 \\
\hline Aramidic (Kevlar 49) & 131 & $3.6-4.1$ & 1.44 & 2.8 \\
\hline
\end{tabular}

* Mesophase pitch-based carbon fibre

A lamina is assumed to behave orthotropically. The overlapping of several laminae with various fibre orientations makes up a laminate (Figure 6.2). The sequence of fibre orientations in the various laminae must be precisely defined as it influences the mechanical behaviour.

In fact, the overlapping of several orthotropic laminae can create a laminate with orthotropic or anisotropic behaviour, depending on the various orientations and the different positions within the thickness of the laminate. The study of the behaviour of laminates is known as macromechanics.

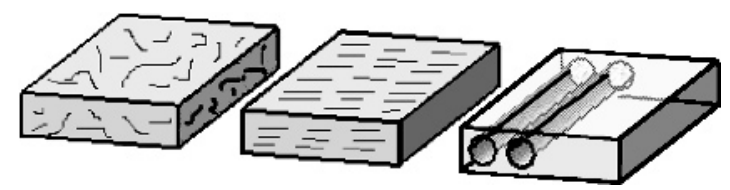

Figure 6.1. Fibre disposition in a lamina of a fibre-reinforced composite 


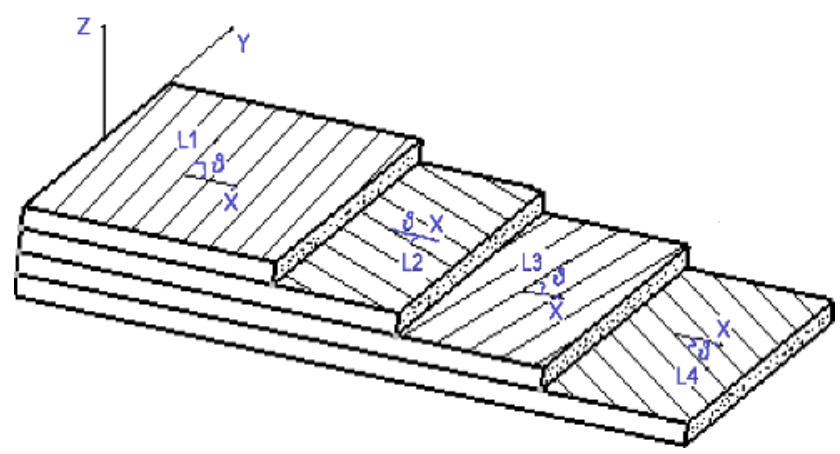

Figure 6.2. Overlapping of several laminae to form a laminate

Table 6.3. Properties of conventional structural materials and fibre composites with fibre volume fraction of $60 \%$

\begin{tabular}{|l|l|l|l|l|l|l|}
\hline & $\begin{array}{l}\text { Tensile } \\
\text { modulus } \\
(\boldsymbol{E}) \\
(\mathbf{G P a})\end{array}$ & $\begin{array}{l}\text { Tensile } \\
\text { strength } \\
\left(\sigma_{\boldsymbol{u}}\right) \\
(\mathbf{G P a})\end{array}$ & $\begin{array}{l}\text { Density } \\
(\boldsymbol{\rho}) \\
(\mathbf{g} / \mathbf{c m} 3)\end{array}$ & $\begin{array}{l}\text { Specific } \\
\text { Modulus } \\
(\boldsymbol{E} / \rho)\end{array}$ & $\begin{array}{l}\text { Specific } \\
\text { strength } \\
\left(\sigma_{\boldsymbol{u}} / \rho\right)\end{array}$ & $\begin{array}{l}\text { Ultimate } \\
\text { elonga- } \\
\text { tion } \\
(\mathbf{\%})\end{array}$ \\
\hline Mild steel & 210 & $0.45-0.83$ & 7.8 & 26.9 & $\begin{array}{l}0.058- \\
0.106\end{array}$ & $38-50$ \\
\hline Aluminium & 70 & $0.26-0.41$ & 2.7 & $25.5-27.0$ & $\begin{array}{l}0.096- \\
0.152\end{array}$ & $30-40$ \\
\hline E-Glass epoxy & 21.5 & 0.57 & 1.97 & 10.9 & 0.26 & 2.5 \\
\hline E-Glass polyester & 22.1 & 0.38 & 1.61 & 13.7 & 0,23 & 3.4 \\
\hline Kevlar 49-epoxy & 40 & 0.65 & 1.4 & 29.0 & 0.46 & 1.8 \\
\hline Carbon fibre-epoxy & 90 & 0.38 & 1.54 & 58.4 & 0.25 & 1.0 \\
\hline
\end{tabular}

\subsubsection{The Importance of Drilling}

In most cases a composite part needs to be assembled to other parts, either in composite or in a different material (steel, aluminium alloys, wood, etc.). Since composite materials cannot be welded, and glueing is quite complex (and cannot be disassembled), mechanical joining (rods, pins, fasteners, rivets, etc.) is the solution commonly adopted to assemble a composite part to other parts (Figure 6.3).

The holes required by mechanical joining are generally drilled in the semifinished composite part. This procedure is generally preferred to the one where a core is placed in the mould during the curing phase. Only large-diameter or complex contour holes are manufactured using this technique.

Since a composite part should perfectly match with the other parts during the assembly phase, holes must be placed in the exact position required, and must have the correct diameter. Moreover, due to their load transfer commitment once in use, holes generally undergo intense localised stress. Consequently, holes are generally subjected to specifications both in geometrical and mechanical terms. 


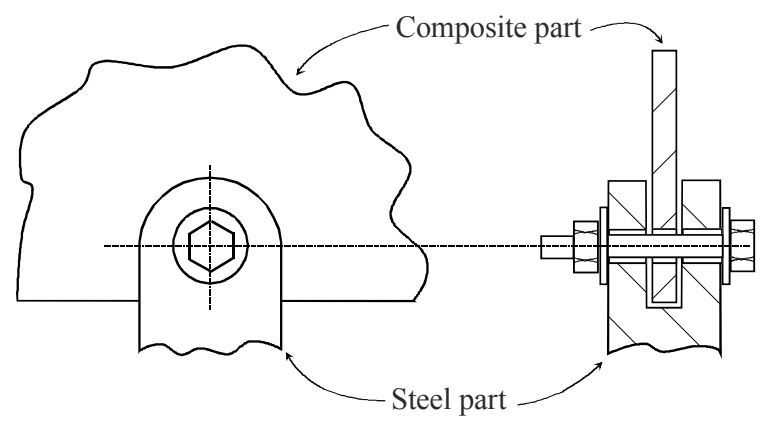

Figure 6.3. Mechanical joining of a composite part

Geometric specifications are the same as the usual given on holes drilled in other materials. They generally consist of specifications on dimension (diameter), position (of the hole centre) and shape (roundness, cylindricity and straightness). Microgeometry (i.e., roughness) con be subject to a specification too, and is generally given in terms of the roughness of the cylindrical surface of the hole. Roughness, cylindricity and straightness specifications are seldom used on thin composite laminates. All these specifications must be reported on the mechanical drawings following the active ISO standards.

The mechanical properties that the material presents around the drilled hole are generally different from (i.e., lower than) the ones that can be found far from the hole. This is because drilling is an invasive process and the material around the hole undergoes structural damage that will be described later. The term residual mechanical properties is generally used to describe the mechanical properties that the material around the hole presents after the drilling process.

The residual mechanical properties strongly depend on how the hole has been drilled. Abusive parameters can deeply damage the material around the hole, thereby leading to limited residual mechanical properties and a hole that cannot withstand the required mechanical load and will fail once in use.

Mechanical specifications are more seldom used in composite manufacturing, and no standards exist for their expression on mechanical drawings. Generally speaking, the material around a hole must withstand a sufficient static load and have an adequate fatigue limit. These characteristics must be present both at the end of the manufacturing phase and during the whole life of the part.

To summarise, it can be stated that drilling conditions and parameters strongly influence the quality of the drilling process from both the mechanical and geometrical point of view. Poor hole quality was estimated to cause $60 \%$ of composite part rejection during quality control in the composite manufacturing industry. This rejection is particularly severe from the economic point of view since it occurs in the last phases of production when the manufacturing cost of the composite part has already been faced.

Consequently, a carefully designed drilling process is the first step to obtaining an economic composite part that can be assembled and is fail safe. 


\subsection{Drilling Technology of Polymeric Matrix Composites}

\subsubsection{Conventional Drilling Process}

\subsubsection{The Twist Drill}

The most commonly used tool in the conventional drilling of composite materials is the twist drill (Figure 6.4), generally obtained in high-speed steel (HSS). The twist drill [19-21] is made up of a cylindrical shank into which two opposite helical grooves have been cut, forming two cutting lips at the end surface ( $\mathrm{AB}$ and $\mathrm{CE}$ ). A central chisel edge (AC) is present near the drill axis to connect the two cutting lips.

The flank $(\alpha)$ and rake $(\gamma)$ angles (described in Chapter 2) play an important role in PMCs drilling, as they influence the hole quality.

In fact in drilling the angles $\alpha_{\mathrm{f}}$ and $\gamma_{\mathrm{f}}$ observed in the feed plane of the tool-inhand reference system (Figure 2.4) may differ substantially from the ones ( $\alpha$ and $\gamma)$ observed in the tool-in-use reference system.

Considering Figure 6.5, it can be observed that a generic point on the cutting lip rotates with a tangential speed of $v_{t}[\mathrm{~m} / \mathrm{s}]$ :

$$
v_{t}=\omega \cdot r=\frac{2 \pi}{60 \cdot 1000} n \cdot r
$$

where $\omega[\mathrm{rad} / \mathrm{s}]$ is the rotation velocity, $n$ is the revolution per minute [rpm] and $r$ $[\mathrm{mm}]$ is the distance of the considered point from the drill axis. Therefore, it can be observed that in drilling the cutting speed varies along the cutting lip: it is at its maximum value on the periphery of the drill and decreases to zero on the axis.
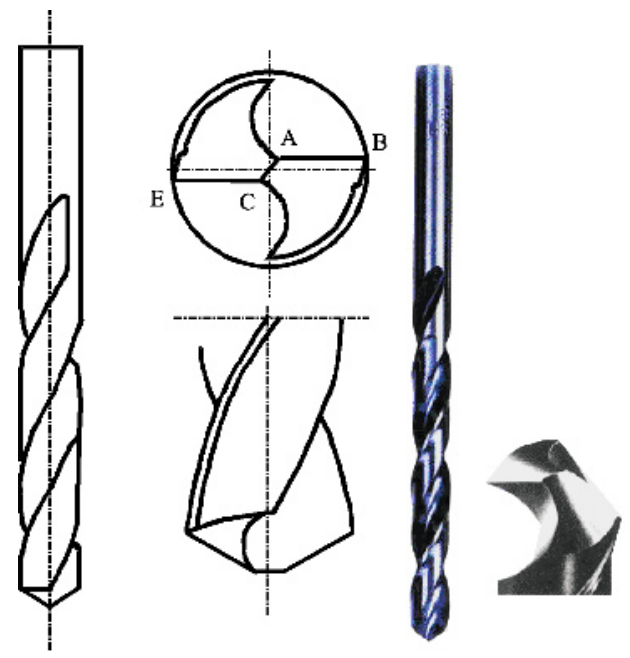

Figure 6.4. Characteristic parameters of a twist drill 


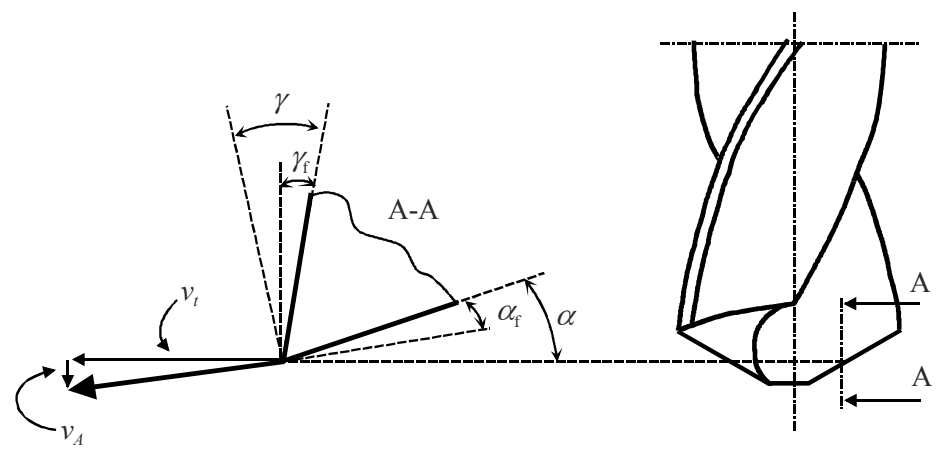

Figure 6.5. Relief and rake angles of a twist drill cutting lip

The same lip point is fed along the drill axis at a speed $v_{A}[\mathrm{~m} / \mathrm{min}]$ given by:

$$
v_{A}=\frac{1}{60 \cdot 1000} f \cdot n
$$

where $f[\mathrm{~mm} / \mathrm{rev}]$ is the feed rate.

It can be easily observed that that the tool-in-use angles are related to the toolin-hand feed rate plane angles through the following relationship (Figure 6.5):

$$
\begin{aligned}
& \gamma=\gamma_{f}+\tan \left(\frac{v_{A}}{v_{t}}\right)=\gamma_{f}+\tan \left(\frac{f}{2 \pi r}\right) \\
& \alpha=\alpha_{f}-\tan \left(\frac{v_{A}}{v_{t}}\right)=\alpha_{f}-\tan \left(\frac{f}{2 \pi r}\right)
\end{aligned}
$$

As the considered point on the cutting lip is moved closer to the drill axis, $r$ becomes small, and special care must be given to avoid negative values of the flank angle $\alpha$. If the flank angle becomes negative there is no longer a cutting action by the lips but the twist drill acts like a punch. In PMCs drilling with punching action is particularly dangerous as it leads to the damage of the material, which dramatically reduces the structural integrity of the material around the hole.

Negative values are generally avoided by adopting a proper tool geometry $\left(\alpha_{\mathrm{f}}\right.$ increases from the periphery to the axis while $\gamma_{\mathrm{f}}$ decreases) and by selecting low feed rates.

\subsubsection{Wear of the Twist Drill}

One of the main limitations when drilling PMCs with the conventional HSS twist drill is the excessive wear experienced by the tool. In fact, while a HSS twist drill can be used to drill hundreds of holes in carbon steel before being worn out, in PMCs drilling the same drill may last for fewer than ten holes.

This rapid wear is due to the abrasive nature of the reinforcement fibres, and is present regardless of the shape or length of the fibres. The wear generally increases with the fibre volume fraction and hardness. 
Tool wear has a significant effect on hole damage as the thrust force increases as tool wear proceeds.

\subsubsection{Thrust Force}

During drilling, a vertical force, that is, a thrust force, is generated. This thrust force can be considered as the sum of several components, each one rising either from the cutting process or from the friction between material and cutting tool (Figure 6.6).

The cutting process occurs along the cutting lips and at the chisel edge. The cutting process along the lips generates a force on each lip that has a component $F_{c l, A}$ parallel to the axis of the drill, that is, the feed direction. Moreover, the chisel edge generates a vertical penetration force, called $F_{c e}$.

The friction forces arise from two components. The first is related to the friction between the side surface of the tool and the generated hole surface, which leads to the vertical force $F_{s s}$. The second component is related to the friction between the chip flow along the helical grooves, which generates the vertical force $F_{h g}$.

The total axial thrust force acting on the drill is therefore:

$$
F_{A}=2 F_{c l, A}+F_{c e}+F_{s s}+F_{h g}
$$

as $F_{c l, A}$ is generated on both cutting lips.

The thrust force observed during drilling not only depends on the geometry of the drill and on the type of material and laminate being worked upon, but also on the relationship between the feed rate and the cutting speed, as well as on the degree of wear of the drill [22-24].

In Figure 6.7 a qualitative trend of thrust force $F_{A}$ as a function of the drilling time $t$ is shown. As can be seen, most of the time the thrust force is positive, that is, a pushing action is exerted by the drill on the workpiece. In the first period the thrust force continues to increase as an increasing part of the cutting lips is engaged in the material; in the second phase the thrust force remains at an almost
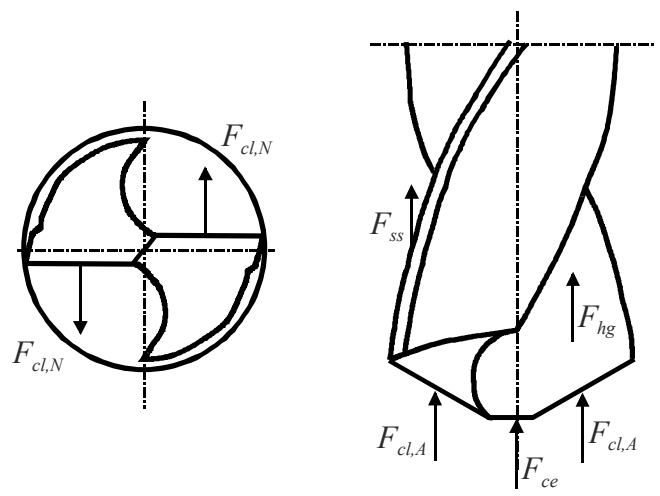

Figure 6.6. Thrust forces during drilling 


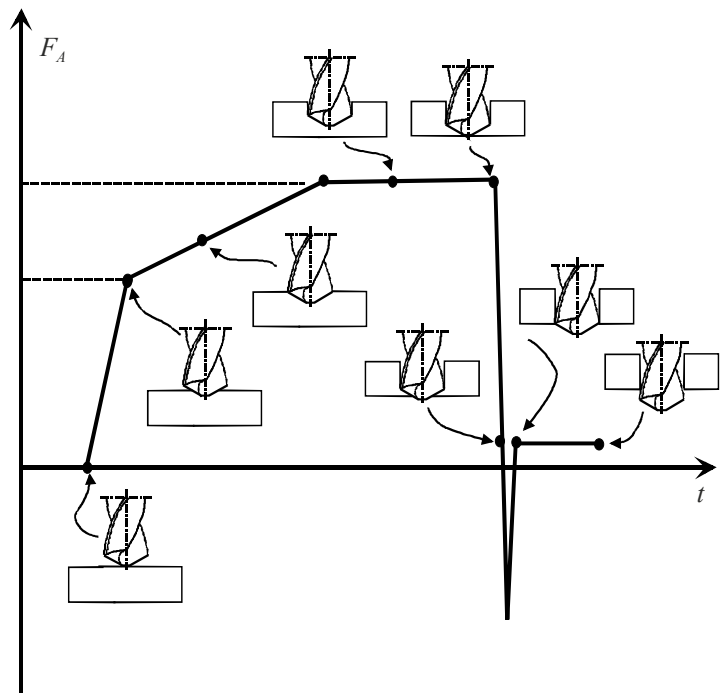

Figure 6.7. General trend of the thrust force as a function of drilling time

constant value as the drill sinks into the workpiece. In the third phase the thrust force rapidly decreases when the twist drill exits, sometimes causing a negative thrust force, that is, a pulling force.

The actual level of the force depends on the material being drilled, on tool geometry, material and wear, and on process parameters. An experimental measure of the thrust force as a function of feed rate is reported in Figure $6.8[25,26]$.

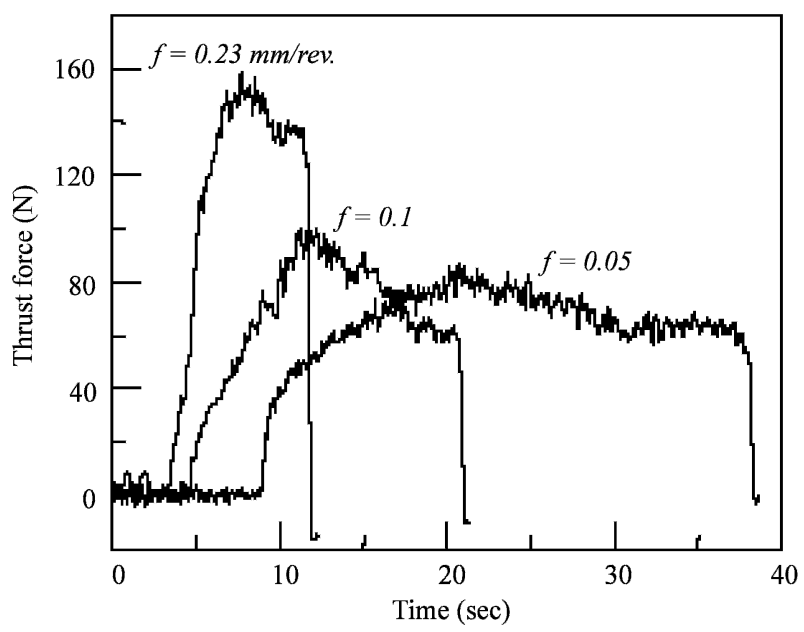

Figure 6.8. Experimental trend of the thrust force as a function of drilling time and feed rate [26] 


\subsubsection{Torque}

During drilling also a torque $T$ is generated, once again being due to the cutting process and to friction.

The cutting torque is due to the horizontal component $F_{c l, N}$ (normal to the cutting lip, see Figure 6.6) of the cutting force. This force is applied somewhere along the cutting lip; as a first approximation it can be supposed to be applied at half the radius. Therefore, the cutting torque is:

$$
T_{c}=2 \frac{r}{2} F_{c l, N}=r \cdot F_{c l, N}
$$

The frictional torques are due to the torque generated by the friction between the chisel edge and the workpiece $\left(T_{c e}\right)$, the friction between the side surface of the drill and the inside hole surface $\left(T_{s s}\right)$ and to the friction of the chip flow along the two helical grooves $\left(T_{h g}\right)$.

The total torque value is:

$$
T=T_{c}+T_{c e}+T_{s s}+T_{h g}
$$

A typical trend of torque as a function of drilling time is shown in Figure 6.9.

As can be seen, the torque initially increases rapidly in a linear manner up to the value $T_{i}[25,26]$. This is due to the fact that an increasing part of the cutting lips is involved in the process This is the part of the torque which is effectively due to the cutting operation.

Subsequently, a further but less steep linear increase in torque can be noted up to value $T_{\max }$. This increase is mainly due to the torque which is generated by friction between the lateral surface of the drill and the inside surface of the hole.

In the final phase of the process, when the drill breaks through the lower surface of the workpiece, the only remaining torque is related to friction between the

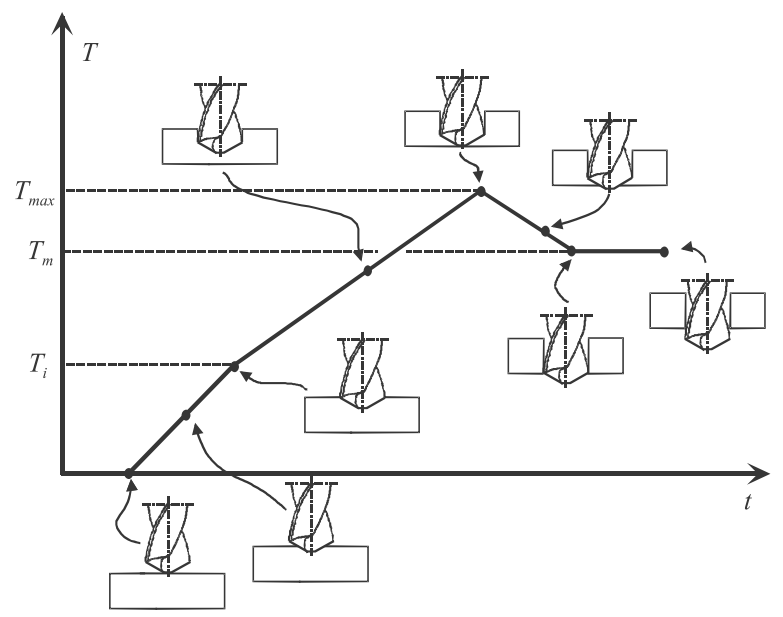

Figure 6.9. Trend of torque during drilling as a function of drilling time 


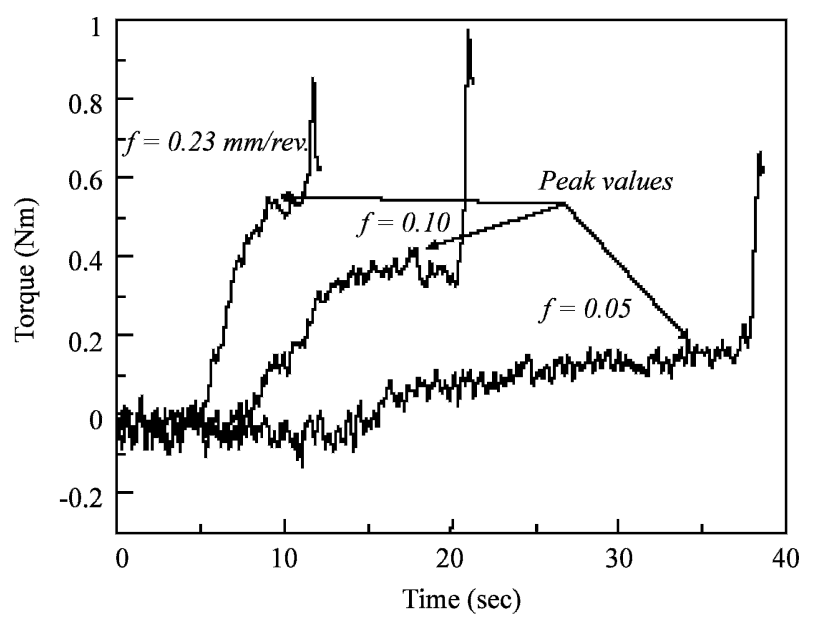

Figure 6.10. Experimental measure of torque during drilling as a function of drilling time and feed rate [26]

lateral surface of the drill and the inside surface of the hole. Consequently, the torque decreases to a value of $T_{m}$ and remains constant.

As for the thrust force, the actual torque depends on the material being drilled, on several process parameters, on the tool shape, material and wear, and on the fixture system. A torque measurement obtained at different feed levels is reported in Figure 6.10.

\subsubsection{Unconventional Drilling Processes}

The main unconventional processes that can be used in composite drilling are laser cutting, water jet (WJ) cutting and abrasive water jet (AWJ) cutting.

In laser cutting, $\mathrm{CO}_{2}$ and $\mathrm{Nd}: \mathrm{YAG}$ resonators are generally used (at wavelengths of $10.6 \mu \mathrm{m}$ and $1.064 \mu \mathrm{m}$, respectively), even though the $\mathrm{CO}_{2}$ resonators are far more frequently applied, as the $10.6 \mu \mathrm{m}$ wavelength is very well absorbed by polymer-based materials. Typical power ranges from $50 \mathrm{~W}$ to $1 \mathrm{~kW}$. The generated laser beam is focussed on the surface with a spot of about $0.2 \mathrm{~mm}$ diameter, therefore yielding a power density (power per unit of exposed surface) as high as $10^{2}-10^{4} \mathrm{~W} / \mathrm{cm}^{2}$. This power density very rapidly heats the exposed material, which generally vaporises in less than ten milliseconds. Therefore, laser cutting is basically a thermal process.

If the diameter of the hole to be drilled is small (say from $0.1 \mathrm{~mm}$ up to $2 \mathrm{~mm}$ ), the process can be performed without relative movement between the beam and the workpiece. For larger hole diameters a hole is first pierced in the material and then the beam contours the circular profile of the hole. This is actually a cutting action of the beam.

Although interesting for the absence of contact between tool and workpiece, which leads to the absence of cutting forces or tool wear, laser cutting presents some drawbacks that must be carefully considered. 
The main limit of laser processing is that the maximum thickness that can be cut with reasonable quality is about $5-10 \mathrm{~mm}$. Above this thickness an evident taper can be observed. Moreover, since laser cutting is a thermal process, thermal damage can be experienced around the drilled hole. Furthermore, since composites are actually made of two different materials that present different thermal properties (matrix and reinforcement), poor hole quality can be generally observed.

In WJ cutting a highly pressurized jet (up to $500 \mathrm{MPa}$ ) is formed through a sapphire orifice (diameter $0.05-0.3 \mathrm{~mm}$ ) and can travel at close to twice the speed of sound in air (about $500 \mathrm{~m} / \mathrm{s}$ ). The formed jet directly impinges on the composite surface and removes material through a set of complex physical mechanisms, where cavitation plays the main role.

The hole pierced by WJ cutting is generally too small for many mechanical fasteners, as the diameter of the hole is the same size as the orifice diameter. Therefore, holes are generally machined using a contour technique.

The main advantages of WJ cutting derive from the absence of tool wear and from the very limited force exerted by the jet on the workpiece. On the other hand, some delamination may occur, especially when piercing a composite laminate.

AWJ is similar to WJ, but the water jet is mixed with a flow of natural or synthetic abrasive particles (mass flow rate $100-800 \mathrm{~g} / \mathrm{min}$ ). The abrasive particles are then accelerated inside a carbide nozzle (diameter about $1 \mathrm{~mm}$ ) by the water jet, and the speed of the particles is believed to reach a speed slightly below the speed of sound (about $250 \mathrm{~m} / \mathrm{s}$ ). The result is a jet of water and abrasive particles that can cut the composite through an erosion mechanism (it can actually cut almost any material, ranging, for example, from steel to concrete).

The maximum thickness that can be drilled and cut can be much higher than in laser or in WJ cutting (up to say $200 \mathrm{~mm}$ ) and very limited delamination is observed even in piercing.

Apart from drilling, these energy beam processes can also be used to trim the composite contour after curing or to cut slots in the manufactured part (such as, the visor window in a composite motorcycle helmet).

\subsection{Modelling of Conventional Drilling}

\subsubsection{The Need for Modelling}

As will be discussed later, several types of damages that can be observed in composite drilling can be directly related to cutting force and torque. In particular, delamination can be related to the thrust force during drilling. Therefore, it is particularly important to model the cutting action and to derive an analytical model that predicts the thrust force as a function of process parameters.

The cutting action of a twist drill is a complex process of oblique threedimensional cutting. The cutting speed and the rake and relief angles vary with the radial distance $\rho$ along the cutting lips of the drill, therefore the process conditions vary noticeably along the cutting lips. 


\subsubsection{Cutting Force Modelling}

Many studies are available in literature dealing with the modelling of the metal drilling process, and reference to Merchant's shear plane model [9] is present in all of them. Unfortunately, all models developed for metals have proved to be unsuitable for composites, as the cutting mechanism is different [10-15]. Consequently, a tailored set of model for drilling PMCs had to be developed.

Since it was experimentally observed that $2 F_{c l, A}>F_{c e}>>F_{s s} ; F_{h g}$, only the action of the cutting lips and of the chisel edge is generally considered in modelling, and the other two forces are neglected.

Since the cutting process varies along the cutting lip, each cutting lip can be described as being composed of several infinitesimal elements aside one other. On each element a orthogonal cutting process occurs, which is characterised by different process parameters and different forces.

The cutting force per unit of lip length generated in the orthogonal cutting of composite materials can be divided into two components, one parallel to the cutting velocity $\left(\delta F_{v t}\right)$, the other $\left(\delta F_{v n}\right)$ perpendicular to it (Figure 6.11). These two components can be predicted using the following experimental relationships [16-18]:

$$
\begin{gathered}
\delta F_{v n}=B \cdot 10^{-a \gamma} \cdot t_{1}^{0.5} \\
\delta F_{v t}=A+B \cdot 10^{-b \gamma} \cdot t_{1}
\end{gathered}
$$

where $t_{1}$ is the thickness of the uncut chip and $A, B, a$ and $b$ are four experimental coefficients that mainly depend on the machined material.

The $F_{c l, N}$ force, acting normal to the cutting lip, and the $F_{c l, A}$ force, acting parallel to the twist drill axis, can be obtained by adding together the contributions of the unitary forces $\delta F_{v t}$ and $\delta F_{v t}$, using an integration operation along the whole cutting lip $[15,16]$ (Figure 6.12):

$$
\begin{aligned}
F_{A} & =2 \cdot \int_{\tau}^{1} \delta F_{v n}\left(1-\frac{w^{2} \sin ^{2}(\varepsilon / 2)}{2 \rho^{2} R^{2}}\right) R \sin (\varepsilon / 2) d \rho \\
& =2 \cdot \int_{\tau}^{1} B \cdot 10^{-a \gamma}(f / 2)^{0.5}\left(1-\frac{w^{2} \sin ^{2}(\varepsilon / 2)}{2 \rho^{2} R^{2}}\right) R \sin (\varepsilon / 2) d \rho \\
T & =2 \cdot \int_{\tau}^{1} \delta F_{v t}\left(1-\frac{w^{2} \sin ^{2}(\varepsilon / 2)}{2 \rho^{2} R^{2}}\right) \rho R^{2} d \rho \\
& =2 \cdot \int_{\tau}^{1}\left[A+B \cdot 10^{-b \gamma}(f / 2)\right]\left(1-\frac{w^{2} \sin ^{2}(\varepsilon / 2)}{2 \rho^{2} R^{2}}\right) \rho R^{2} d \rho
\end{aligned}
$$

where the integration variable is $\rho=r / R$ and the integration limits can be obtained from Figure 6.13. 


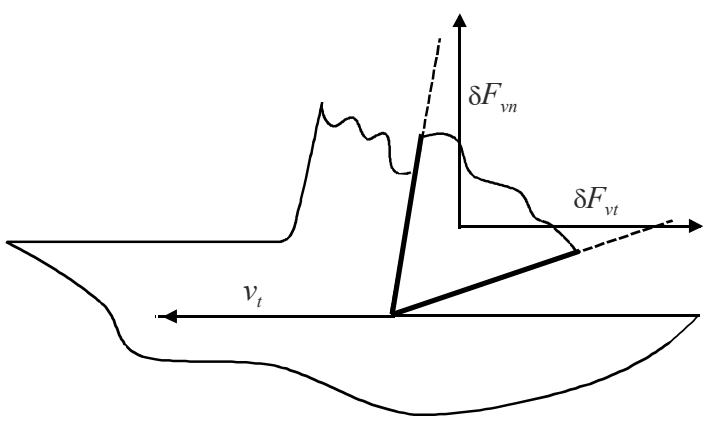

Figure 6.11. Orthogonal cutting condition and forces per unit of cutting lip length

The actual rake angle, $\gamma$, is given by the sum of two addends as described by Equation (6.3). Since the closed analytical solution of Equations (6.10) and (6.11) is too complex, it is possible to adopt an average rake angle, $\gamma_{m}$, expressed as:

$$
\gamma_{m}=\frac{\int_{\tau}^{1}\left(\gamma_{f}+\tan ^{-1}\left(\frac{f}{2 \pi \rho R}\right)\right) d \rho}{\int_{\tau}^{1} d \rho}
$$

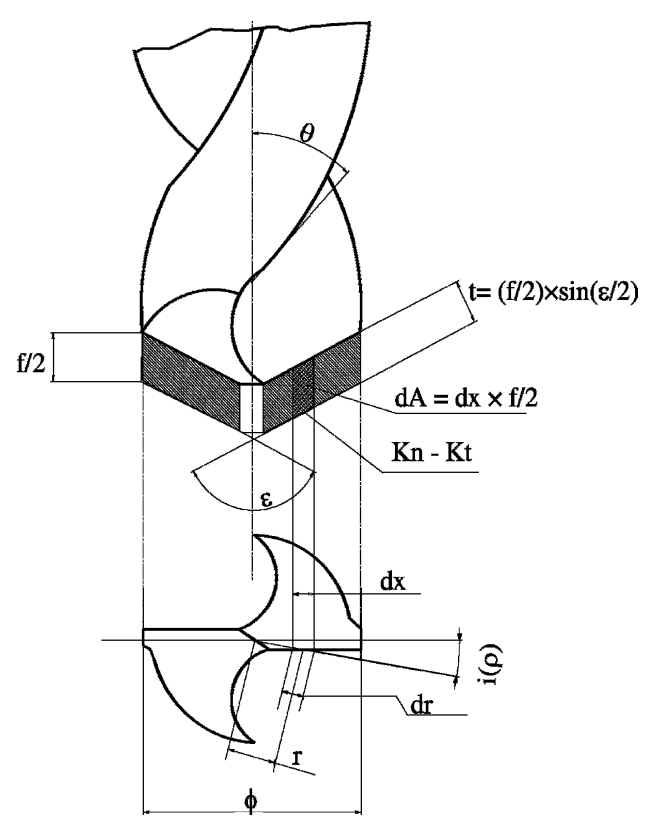

Figure 6.12. Twist drill and relevant parameters 


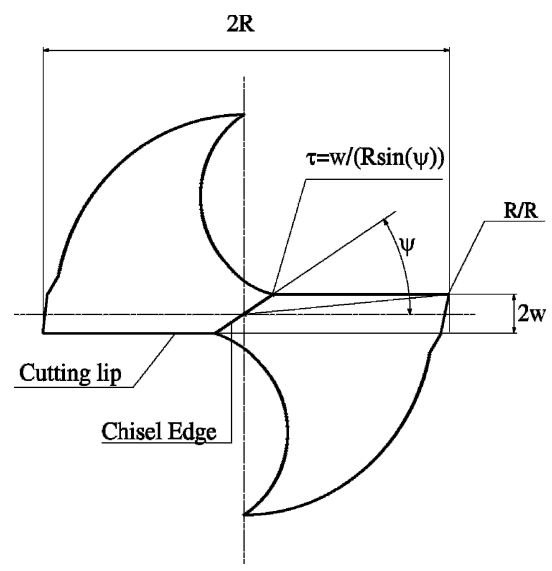

Figure 6.13. Twist drill seen from below

Thus, the following quantities con be determined:

$$
\begin{array}{r}
G=\int_{\tau}^{1}\left[1-\frac{w^{2} \sin ^{2}(\varepsilon / 2)}{2 \rho^{2} R}\right] R^{2} \rho d \rho=\frac{1}{2}\left[\left(1-\tau^{2}\right) R^{2}+w^{2} \sin ^{2}\left(\frac{\varepsilon}{2}\right) \ln \tau\right] \\
G^{\prime}=\int_{\tau}^{1}\left[1-\frac{w^{2} \sin ^{2}(\varepsilon / 2)}{2 \rho^{2} R}\right] R \sin (\varepsilon / 2) d \rho=\frac{\sin \left(\frac{\varepsilon}{2}\right)(1-\tau)\left[2 \tau R^{2}-w^{2} \sin \left(\frac{\varepsilon}{2}\right)\right]}{2 \tau R}
\end{array}
$$

The value of the thrust force and of the torque can be calculated using the simplified relations:

$$
\begin{gathered}
T^{\prime}=2 \cdot B \cdot 10^{-b \gamma_{m}} \cdot(f / 2)^{0.5} \cdot G^{\prime} \\
M^{\prime}=2 \cdot\left[A+B \cdot 10^{-b \gamma_{m}} \cdot(f / 2)\right] \cdot G
\end{gathered}
$$

In a similar way it is possible to evaluate the contribution of the chisel edge to the thrust force (the contribution to the torque is negligible) [16]:

$$
T=C \cdot 10^{-c \cdot \gamma_{\text {chisel }}} \cdot f^{0.5} \cdot 2 w
$$

where $C$ and $c$ are two experimental coefficients.

The identified model was verified for glass fiber reinforced plastic (GFRP) laminates and theoretical values have shown a good correspondence to the experimental ones, as can be seen in Figure 6.14 [16]. 

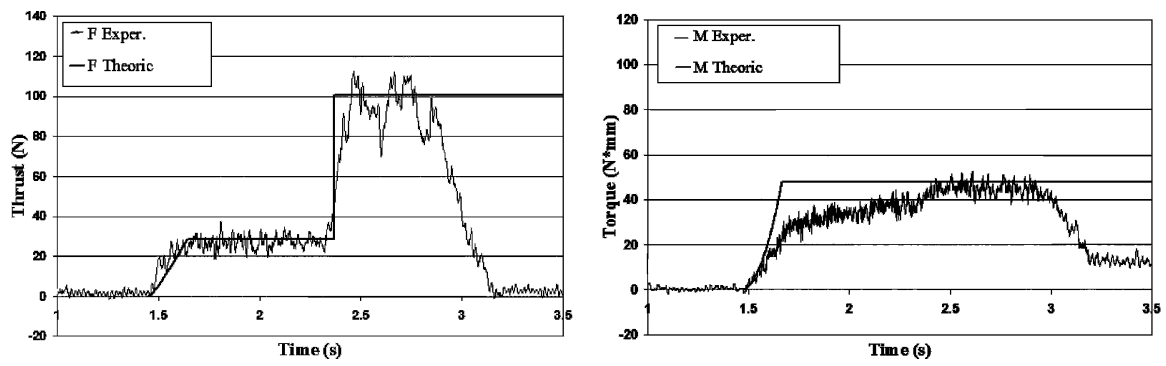

Figure 6.14. Typical run of the theoretical-experimental comparison of thrust and torque $n=1250 \mathrm{rpm} ; f=0.25 \mathrm{~mm} / \mathrm{rev} ; \varepsilon=140^{\circ} ; \theta=30^{\circ}$

\subsection{Damage Generated During Drilling and Residual Mechanical Properties}

\subsubsection{Structural Damage}

The main types of structural damage generated during drilling of polymeric matrix composites are delamination, microcracks, fibre-matrix debonding, matrix cratering and thermal damage ${ }^{1}$. The presence and extension of the different kinds of damage depend on the composite material characteristics, tool geometry and material, and the process parameters [27-36]. The damage is particularly detrimental to the residual mechanical properties and significantly reduces the composite performance in use. Consequently, special care should be given to avoid the generation of defects during drilling.

\subsubsection{Damage Evaluation Methods}

Different techniques and parameters can be used to assess the damage caused by drilling $[27,33,39,40]$. Sophisticated non-destructive techniques can be employed in addition to low-magnification microscopy in order to identify internal defects, while destructive techniques are rarely employed. Moreover, a scanning electron microscope can be used to observe the cut surface morphology [28,29].

There are various methods for delamination evaluation. On semi-transparent composites, a coloured liquid can be used to penetrate the material through the cut surface. The extent of the damage around the hole is highlighted by the contrasting colours and can be measured using an optical microscope. In [39] an ultrasonic $\mathrm{C}$-scan technique is used, but X-ray computerized tomography (CT) can also be successfully used, as mentioned by the author.

In [33] the principal parameters used to characterize delamination after drilling are discussed. One group of authors tends to use dimensional parameters, such as delamination area or length, while another proposes non-dimensional parameters

\footnotetext{
${ }^{1}$ Unfortunately there is no consistency in the terminology used in the literature, and care should be taken to compare the damage described by different authors.
} 
(ratio of damage area to the hole area, ratio of the drill radius to the delamination radius, etc.).

\subsubsection{Delamination}

Delamination is the damage which is most evident after drilling composite materials. It consists of local debonding around the drilled hole of one or more plies (Figure 6.15).

Delamination is commonly classified as peel-up delamination at the twist drill entrance and push-down delamination at the twist drill exit (Figure 6.16).

Peel-up delamination at drill entry is not always present. Push-down delamination is generally more extensive and is consequently considered to be the most dangerous. The last plies of composite tend to open up as the drill pierces through the laminate while generating a hole. This happens because the last lamina undergo a push-down action, thus debonding the plies interface.

Several phenomena contribute to the delamination mechanism. It is assumed that delamination mainly depends on the thrust force exerted by the drill point. The process parameters play a main role in determining the thrust force, and consequently the extent of delamination.

The influence of the drilling parameters and tool geometry has been assessed for different fibre-reinforced composites.

Caprino and Tagliaferri [29] assert that the damages observed after drilling GFRP with an HSS drill are strongly affected mainly by the feed rate. Furthermore, Tagliaferri et al. [28] indicate that the GFRP damage depends on the ratio between rotation speed and feed rate, irrespective of reinforcement form, resin type and fabrication method.

Capello and Tagliaferri [32] show that the degree of peel-up delamination depends on the feed rate and on the helix angle of the twist drill. Push-down delamination is mainly affected by the feed rate, by the presence of a support beneath the specimen and by the twist drill temperature.

In aramid composite drilling, a linear relationship exists between feed rate, thrust force and push down delamination, as proposed by Veniali et al. [31]. With regard to the tool geometry, the chisel edge width seems to be the most important factor that contributes to the thrust force and hence to the occurrence of delamination, as shown by Jain and Yang [36]. The point angle is of minor significance.

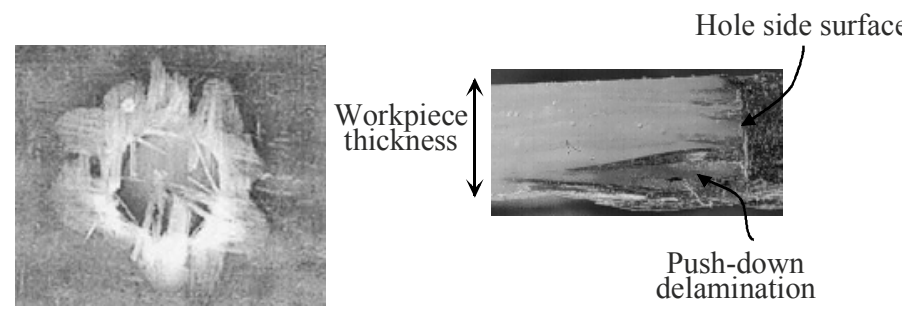

Figure 6.15. Delamination around a drilled hole: bottom view (left) and cross section (right) 

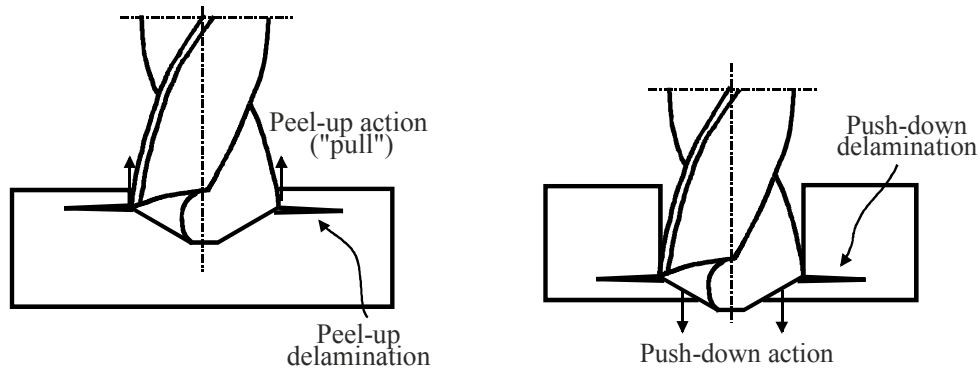

Figure 6.16. Delamination at the twist drill entrance (left) and exit (right) when drilling PMCs laminate

Davim and Reis [45] studied the effect of two distinct geometries of cemented tungsten carbide drills on carbon-fibre-reinforced plastic (CFRP) laminates. The authors concluded that delamination at the drill entry and exit are affected by distinct parameters, i.e., at drill entry feed rate was the most significant factor affecting delamination whereas at the drill exit, delamination was primarily affected by cutting speed.

\subsubsection{Modelling Delamination}

A model predicting push-down delamination was identified using the classical plate-bending theory and linear elastic fracture mechanics [40-44].

The model describes the last stage of drilling as schematically reported in Figure 6.12. At this point the twist drill exerts a force (thrust force $F_{A}$ ) on the last lamina, which can be considered as a circular plate subject to a point central load.

When the drill is fed downwards, the delamination propagates. In energetic terms, the work done by the thrust force is used to bend the free part of the last lamina (similar to a circular plate) and to widen the intra-lamina crack, that is, the push-down delamination.

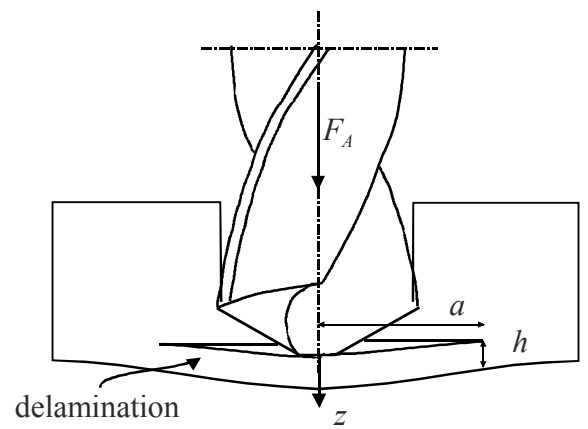

Figure 6.17. Circular plate model for delamination analysis 
Therefore, the energy balance equation can be written as:

$$
G_{I C} d A=F_{A} d z-d U
$$

where $z$ is the vertical displacement, $d U$ is the infinitesimal strain energy, $d A$ is the increase in the area of the delamination crack and $G_{I C}$ the critical crack propagation energy per unit area in mode I.

If an isotropic behaviour and a pure bending of the laminate are assumed, for a circular plate clamped at its periphery the stored strain energy $U$ is [44]

$$
U=\frac{E h^{3}}{12\left(1-v^{2}\right)} \frac{8 \pi z^{2}}{a^{2}}=M \frac{8 \pi z^{2}}{a^{2}}
$$

where $E$ is the modulus of elasticity, $v$ is Poisson's ratio and $M$ is the flexural rigidity of the plate.

The thrust force at the onset of crack propagation can be calculated as:

$$
F_{A, t h}=\pi\left[\frac{8 G_{I C} E h^{3}}{3\left(1-v^{2}\right)}\right]=\pi \sqrt{32 G_{I C} M}
$$

where $h$ is the uncut thickness of the last lamina.

In order to avoid delamination, the applied thrust force should not exceed this threshold value, which is a function of the material properties and the uncut thickness. If the thrust force exceeds the $F_{A, t h}$ value, delamination occurs and propagates.

This model was later extended to various twist drill types, such as saw drill, candle stick drill, core drill and step drill $[48,49]$, where the load exerted by the drill is distributed in a different way.

\subsubsection{Other Types of Damage}

Cratering and thermal alteration of the matrix, pull-out and fuzzing of the fibres and intra-lamina cracks are reported in the literature as other types of damage occurring in a composite material subjected to drilling [29, 30, 32].

The thermal alterations in both fibre and matrix, generally limited to a small volume around the hole, are related to the energy converted into heat by frictional forces. The extent of this thermal damage depends on the thermal conductivity of fibre and matrix. For instance, low thermal conductivity in aramide/epoxy laminates promotes the increase of temperature and possible thermal damage of the material around the hole [30].

Fibre pull-out and fuzzing can be present along the entire hole surface and mainly depend on the fibre orientation and on the feed rate, as well as on the tool geometry.

\subsubsection{Residual Mechanical Properties}

The damage generated during drilling in a PMC laminate is particularly detrimental to the residual mechanical properties. 
In order to obtain a fail-safe composite part the relationship between the drilling parameters and the different kinds of damage must be understood, and the influence of these kinds of damage on the residual mechanical behaviour must be identified.

Some mechanical tests both under static and cyclic load conditions are proposed in the literature to evaluate these relationships [28, 38, 49].

\subsubsection{Evaluation Methods of Residual Mechanical Properties}

The most commonly used method for the evaluation of the residual mechanical properties is the tensile test, i.e., the static and cyclic bearing load tests and the fatigue test.

There are two ways of testing the residual mechanical properties of a drilled composite. One way, referred to as a load test, is to pull a rectangular specimen which has a hole drilled in the centre, at both short ends. The other method, generally referred to as a bearing load test, is to place a pin in the drilled hole and to apply a pulling force to the pin and to one of the short ends (Figure 6.18). In the bearing load test the hole undergoes a localized stress similar to the stress it would probably undergo in use. The result of this test is more sensitive to the level of damage generated during drilling than the results of the conventional load test.

Furthermore, in both tests, the load can be either constant or cyclic. If the load is constant (static bearing load (SBL)), the specimen is elongated until breakage occurs or a given displacement has been imposed. If the load is cyclic (cyclic bearing load (CBL)), it is varied, generally following a sine wave, again until breakage occurs or a given displacement has been imposed.

\subsubsection{Static and Fatigue Resistance}

Several data are available concerning the static and fatigue resistance of GFRP laminate. The results discussed in [28] show that static tensile strength of specimens with a hole is not affected by drilling conditions and consequently by damage, whereas a strong decrease in bearing strength could be observed as the damage around is increased.

In [38] the results of tests with static and cyclic bearing load show that the main cause of mechanical failure is the microdamage generated at the inner part of the hole surface, the influence of delamination being less evident. This underlines the

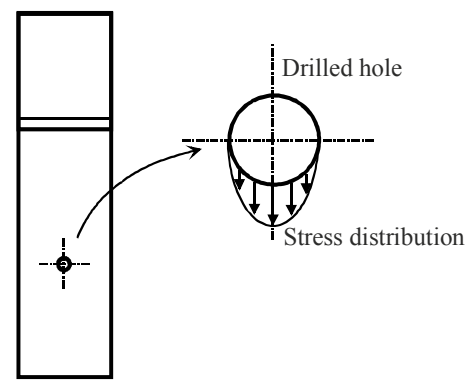

Figure 6.18. Experimental setup used for SBL and CBL tests 
role played by the feed rate, which is the most important process parameter that promotes the generation of microcracks along the whole hole section.

The presence of a support under the material positively affects only the SBL but has a mild effect on the CBL mechanical behaviour. The twist drill preheating, even if it reduces the size of delamination [32], promotes thermal alteration uniformly distributed in the hole section, and therefore has a negative effect in both SBL and CBL.

In [49] the influence of different drilling tool on the fatigue behaviour is discussed. In particular the $\mathrm{S}-\mathrm{N}$ curves are influenced by the used tool and then show a direct correlation between the damage and the fatigue behaviour of the material around the hole.

\subsection{Damage Suppression Methods}

\subsubsection{Introduction}

Damage reduction or suppression can be achieved through:

- a careful selection of process parameter

- an enhancement of drilling conditions

- the use of a special tool.

A careful selection of process parameters is the first step to reducing drilling damage, as this can be done without any particular effort. Drilling conditions may also be varied, but this is not always feasible. It may not be possible to place a predrilled support under the workpiece and align it perfectly with the twist drill axis. Lastly, the standard HSS twist drill tool might be substituted by tools in different materials and with optimised geometries, but these are generally more expensive $[34,51,52]$.

\subsubsection{Process Parameters Selection}

The two parameters that significantly influence the drilling process, and, in particular, the quality of the obtained holes, are the cutting speed $v_{t}$ and the feed rate $f$ $[60,61]$.

An increase in cutting speed results in lower thrust force and torque due to the higher temperatures reached by the tool and the machined material. On the other hand, higher twist drill temperatures negatively influence the internal quality of the hole and the residual mechanical properties.

Large values of feed rate are associated the failure modes typical of impact damage, with step-like delamination, intra-lamina cracks and high-density microfailure zones $[24,30,50,54]$. With intermediate values of feed rate the failure consists essentially in push-down delamination, generated when the chisel edge and the inner portion of the lips have already left the work material [29]. Even lower values of feed rate may lead to a damage-free hole, at least for the supported drilling condition. 


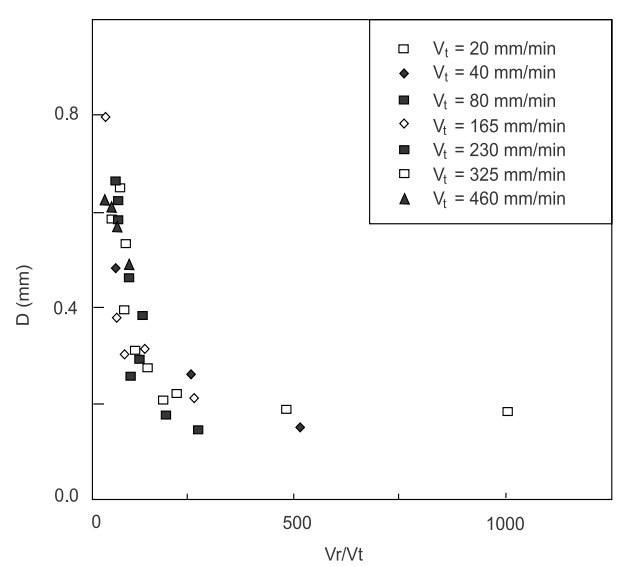

Figure 6.19. Size of delamination zone as a function of the ratio between cutting speed and feed rate [28]

It should be noticed that the type and extension of the damage is strongly influenced by the ratio between the cutting speed $v_{t}$ and feed rate $f$, rather then on the two separately. For large values of the $v t / f$ ratio the internal surface of the hole is smooth and regular with little delamination, both in the case of supported or unsupported drilling; even though in the latter case, the push-out delamination is sensibly wider.

For small values of the $v t / f$ ratio the hole is significantly damaged: the push-out delamination is wider and involves several layers, internal cracks and debonding of the fibres occur. Figure 6.19 reports the size of delamination (in terms of average diameter of the delaminated area) as a function of the ratio between cutting speed and feed rate [28].

The effect of cutting parameters on surface roughness is quite difficult to generalise, as the result is influenced by composite characteristics and, in particular, by fibre volume fraction.

For glass fibre reinforced/epoxy composites the hole surface finish can be improved by increasing cutting speed and fibre volume fraction. Holes drilled with low cutting speed and feed rates exhibit a large roughness. On the other hand, composites with high fibre volume fraction exhibit a contrary behaviour [26].

\subsubsection{Drilling Conditions}

The selection of drilling conditions is concerned with the application of particular cutting methods, such as the use of a pre-heated tool, the presence of a support under the workpiece, the vibration-assisted drilling and the employment of a damper for unsupported drilling.

The use of a pre-heated tool drastically reduces the thrust force, yielding a narrower push-out delamination and a lower energy required to drill the hole. Unfortunately, the thermal damage induced in the material around the hole is stronger and a strong reduction in residual mechanical properties can be observed [40]. Pre- 
cooled tools, on the other hand, present an increase in drill thrust force (and in the probability of delamination), but this drawback is compensated by the improved surface finish, hole quality and far superior tool life [57].

The presence of the support beneath the workpiece significantly reduces the level of the push-out delamination because the threshold thrust force at the onset of delamination is increased, but mildly affects the internal damage. Consequently, a commonly followed practice in the industry is the use of a support on the back to prevent deformations leading to exit delamination [37].

Better quality holes and high efficiency can be obtained by the vibrationassisted cutting technique $[38,55,58]$. Conventional drilling is a continuous cutting process, whereas vibration-assisted drilling is a pulsed intermittent cutting process using a piezoelectric crystal oscillator [59].

In the case of unsupported drilling, delamination can be sensibly reduced by using a damper alongside the twist drill. In fact, the damper greatly reduces the workpiece dynamics, avoiding the fast release movement of the workpiece when the twist drill exits the laminate. Thus the actual feed rate in this particular final phase is reduced and delamination almost eliminated [37].

\subsubsection{Special Tools}

Several geometries of drill tools have been investigated, aiming mainly at the reduction of thrust force and delamination. The most investigated geometries are the candlestick drill, saw drill, core drill and step drill (Figure 6.20) [33, 39, 53, 56].

All these tools were developed with the aim of reducing push-out delamination by reducing the thrust force. In Figure 6.21 the correlation between thrust force and feed rate for various drills is shown.

As can be seen, the drilling thrust of the twist drill is the highest, followed by the saw drill and core drill, while the candlestick drill and step drill are the lowest. This behaviour means that the twist drill is more susceptible to cause delamination damage due to the larger thrust force it generates during drilling.

The peel effect of plies along the edge of the major drill cutting edges takes place when the tool tip encounters the first ply. This defect increases with the rake angle and tends to produce ply detachment [44]. To reduce or eliminate this en-

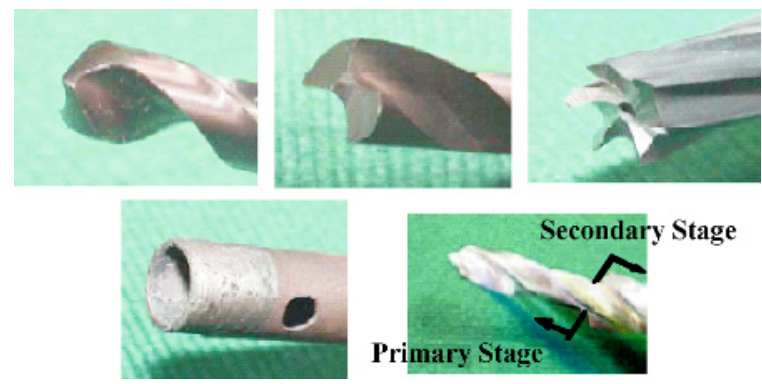

Figure 6.20. Examples of different drilling tool geometries (from left to right): the traditional twist drill, the candle stick drill, the saw drill, the core drill and the step drill 


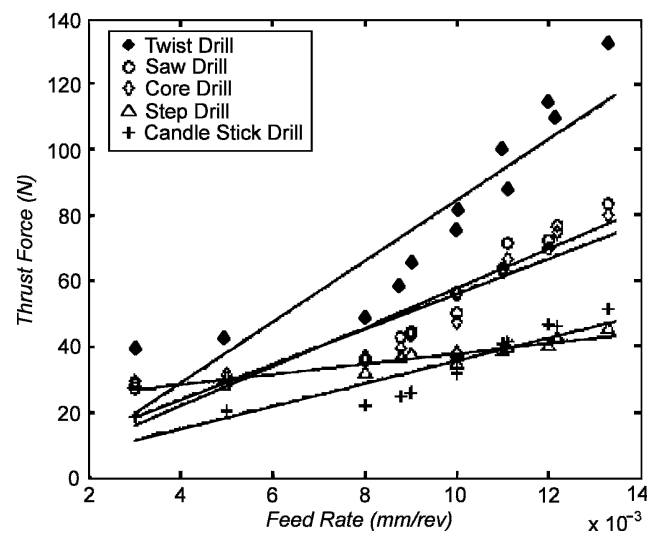

Figure 6.21. Correlation between thrust force and feed rate for special drills [39]

trance defect, a small rake angle prevents the first plate ply from lifting up and tearing off. A rake angle lower than $6^{\circ}$ is usually recommended.

\section{References}

[1] Crivelli Visconti I (1974) Materiali Compositi, Tamburini, Italia

[2] Agarwal BD, Broutman LJ (1980) Analysis and Performance of Fiber Composites. Wiley, New York, NY

[3] Schwartz, MM (1984) Composite Materials Handbook. McGraw-Hill, New York, NY

[4] Ecklod G (1994) Design and Manufacturing of Composite Structures. Woodhead, Cambridge, England

[5] Hollaway L (1994) Handbook of Polymer Composites for Engineers. Woodhead, Cambridge, England

[6] Gürdal Z, Haftka RF, Hajela P (1999) Design and Optimization of Laminated Composite Materials. Wiley, New York, NY

[7] Staab GH (1999) Laminar Composites. Butterworth-Heinemann, Boston, MA

[8] ASM Handbook, Volume 21 Composites (2001) ASM International. Material Park, $\mathrm{OH}$

[9] Merchant ME (1944) Basic mechanics of the metal-cutting process. ASME J Appl Mech 11: 168-175

[10] Oxford CJ (1955) On the drilling of metals-I. Basic mechanics of the process. Trans ASME 77: 103-114

[11] Mauch CA, Lauderbaugh LK (1990) Modeling the drilling process - An analytical model to predict thrust force and torque, computer modeling and simulation of manufacturing processes. ASME Prod Eng Div 48: 59-65

[12] Armarego EJA, Wright JD (1984) Predictive models for drilling thrust and torque a comparison of three flank configurations. Ann CIRP 33: 5-10

[13] Stephenson DA, Agapiou JS (1992) Calculation of main cutting edge forces and torque for drills with arbitrary point geometries. Int J Mach Tools Manuf 132(4): 521-538 
[14] Ehmann KF, Kapoor SG, DeVor RE, Lazoglu I (1997) Machining process modeling: a review. J Manuf Sci Eng 119: 655-659

[15] Chandrasekharan V, Kapoor SG, DeVor RE (1995) A mechanistic approach to predicting the cutting forces in drilling: with application to fiber-reinforced composite materials. J Eng Ind 117: 559-570

[16] Langella A, Nele L, Maio A (2005) A torque and thrust prediction model for drilling composite materials. Compos Pt A 36: 83-93

[17] Caprino G, Nele L (1996) Cutting forces in orthogonal cutting of unidirectional GFRP composites. J Eng Mater Technol 118: 419-425

[18] Caprino G, Nele L, Santo L (1996) On the origin of cutting forces in machining unidirectional composite materials. ASME International. Reprinted from: PD-Vol 75, ESDA Engineering System Design and Analysis Conference, 83-89

[19] Arshinov V, Alekseev G (1973) Metal Cutting Theory and Cutting Tool Design. MIR, Moscow

[20] Spur G, Stöferle T (1987) Enciclopedia delle Lavorazioni Meccaniche, vol. 3 asportazione di truciolo. Tecniche Nuove, Milano

[21] Santochi M, Giusti F (2000) Tecnologia Meccanica e studi di fabbricazione, Casa Editrice Ambrosiana, Milano

[22] Jain S, Yang DCH (1994) Delamination - free drilling of composite laminates. J Eng Ind 116: 475-481

[23] Di Ilio A, Paoletti A, Veniali F (1996) Tool wear in drilling thermosets and thermoplastic matrix composites.Eng Syst Des Anal ASME 3: 41-46

[24] Khashaba UA (2004) Delamination in drilling GFR-thermoset composites. Compos Struct 63: 313-327

[25] Abrate S, Walton DA (1992) Machining of composite material: Part I: Traditional methods. Compos Manuf 2: 75-83

[26] El-Sonbaty I, Khashaba UA, Machaly T (2004) Factors affecting the machinability of GFR/epoxy composites. Compos Struct 63: 329-338

[27] Davim JP, Rubio JC, Abrao AM (2007) A novel approach based on digital image analysis to evaluate the delamination factor after drilling composite laminates. Compos Sci Technol 67:1939-1945

[28] Tagliaferri V, Caprino G, Diterlizzi A (1990) Effect of drilling parameters on the finish and mechanical properties of GFRP composites. Int J Mach Tools Manuf 30 (1):77-84

[29] Caprino G, Tagliaferri V (1995) Damage development in drilling glass fibre reinforced plastics. Int J Mach Tools Manuf 35 (6): 817-829

[30] Di Ilio A, Tagliaferri V, Veniali F (1991) Cutting mechanisms in drilling of aramid composites. Int J Mach Tools Manuf 31 (2): 155-165

[31] Veniali F, Di Ilio A, Tagliaferri V (1995) An experimental study of the drilling of aramid composites. J Energy Resour Technol 117:271-278

[32] Capello E, Tagliaferri V (2001) Drilling damage of GFRP and residual mechanical behavior-part 1: drilling damage generation. J Compos Technol Res 23 (2):122-130

[33] Abrao A M, Faria PE, Campos Rubio J., C., Reis P, Paulo Davim J (2007) Drilling of fiber reinforced plastics: A review. J Mater Process Technol 186:1-7

[34] Jain S, Yang DCH (1993) Effects of federate and chisel edge on delamination in composite drilling. Trans ASME J Eng Ind 115: 398-405

[35] Mathew J, Ramakrishnan N, Naik NK (1999) Investigations into the effect of geometry of a trepanning tool on thrust and torque during drilling of GFRP composites. J Mater Process Technol 91:1-11

[36] Jain S, Yang DCH (1994) Delamination-free drilling of composite laminates. Trans ASME J Eng Ind $116(4): 475-481$ 
[37] Capello E (2004) Workpiece damping and its effect on delamination damage in drilling thin composite laminates. J Mater Process Technol 148:186-195

[38] Capello E, Tagliaferri V (2001) Drilling damage of GFRP and residual mechanical behavior - part 2: static and cyclic bearing loads. J Compos Technol Res 23 (2):131-137

[39] Hocheng H, Tsao CC (2006) Effects of special drill bits on drilling-induced delamination of composite materials. Int J Mach Tools Manuf 46:1403-1416

[40] Tsao CC, Hocheng H (2003) The effect of chisel length and associated pilot hole on delamination when drilling composite materials. Int J Mach Tools Manuf 43:1087-1092

[41] Timoshenko S, Woinowsky-Keiger S (1959) Theory of plates and shells. McGrawHill, New York, NY

[42] Tsao CC, Hocheng H. (2007) Effect of tool wear on delamination in drilling composite materials. Int J Mech Sci 49:983-988

[43] Tsao CC (2006) The effect of pilot hole on delamination when core drill drilling composite materials. Int J Mach Tools Manuf 46:1653-1661

[44] Hocheng H, Dharan CKH (1990) Delamination during drilling in composite laminates. J Eng Ind 112:236-239

[45] Davim JP, Reis P (2003) Drilling carbon fiber reinforced plastics manufactured by autoclave-experimental and statistical study. Mater Des 24 (5):315-324

[46] Won M S, Dharan CK, H (2002) Chisel edge and pilot hole effects in drilling composite laminates. Trans ASME J Manuf Sci Eng 124:242-247

[47] Cantwell WJ, Morton J (1989) Geometrical effects in the low velocity impact response of CFRP. Compos Struct 12:39-60

[48] Hocheng H, Tsao CC (2003) Comprehensive analysis of delamination in drilling of composite materials with various drill bits. J Mater Process Technol 140:335-339

[49] Persson E, Eriksson I, Zackrisson L (1997) Effects of hole machining defects on strength and fatigue life of composite laminates. Compos Pt A, 28: 141-151

[50] Konig W, Wulf C, Grass P, Willerscheid (1985) Machining of fiber reinforced plastics. Ann CIRP 34 (2): 537-548

[51] Velayudham A, Krishnamurthy R (2007) Effect of point geometry and their influence on thrust and delamination in drilling of polymeric composites. J Mater Process Technol 185: 204-209

[52] Tsao CC, Hocheng H (2007) Parametric study on thrust force of core drill. J Mater Process Technol 192: 37-40

[53] Piquet R, Ferret B, Lachaud F, Swider P (2000) Experimental analysis of drilling damage in thin carbon/epoxy plate using special drills. Compos Pt A 31: 1107-1115

[54] Konig W, Grab P, Heintze A, Okcu F, Schmitz-Justen Cl (1985) New developments in drilling and contouring composites containing kevlar aramid fiber, Fabrication of Composite Materials, Source Book edited by M. M. Schwartz, ASM, Metal Park, Ohio, 236

[55] Wang X, Wang LJ, Tao JP (2004) Investigation on thrust in vibration drilling of fiber-reinforced plastics. J Mater Process Technol 148: 239-244

[56] Tsao CC, Hocheng H (2005) Effect of eccentricity of twist drill and candle stick drill on delamination in drilling composite materials. Int $\mathrm{J}$ Mach Tools Manuf 45: $125-130$

[57] Bhattacharyya, Horrigan DP (1998) A study of hole drilling in kevlar composites. Compos Sci Technol 58, 267-283

[58] Arul S, Vijayaraghavana L, Malhotrab SK, Krishnamurthy R (2006) The effect of vibratory drilling on hole quality in polymeric composites. Int J Mach Tools Manuf 46: $252-259$ 
194 E. Capello et al.

[59] Zhang LB, Wang LJ, Liu XY, Zhao HW, Wang X, Luo HY (2001) Mechanical model for predicting thrust and torque in vibration drilling fibre-reinforced composite materials, Int J Mach Tools Manuf 41: 641-657

[60] Chen WC (1997) Some experimental investigations in the drilling of carbon fiberreinforced plastic (CFRP) composite laminates. Int J Mach Tools Manuf 37 (8): 1097-1108

[61] Stone R, Krishnamurthy K (1996) A neural network thrust force controller to minimise delamination during drilling of graphite-epoxy laminates. Int $\mathrm{J}$ Mach Tools Manuf 36 (9): 985-1003 